\title{
La ciudad como cronotopo real histórico y la configuración del espacio de ficción en la novela Angosta del escritor colombiano Héctor Abad Faciolince
}

\author{
The city as a historic chronotopos and the \\ configuration of fictional space in the novel Angosta by \\ the Colombian writer Héctor Abad Faciolince
}

Resumen

\section{Edilson Silva Liévano}

Este artículo corto derivado de investigación presenta un análisis sobre la novela Angosta (2003), del escritor colombiano Héctor Abad Faciolince. El autor recurre a los aportes de la teoría social y a la metodología de la sociocrítica para hacer emerger la configuración del espacio de ficción en la novela. En sí, el trabajo establece relaciones entre el cronotopo real histórico, para este caso la ciudad contemporánea y la configuración axiológica del espacio de ficción presente en la novela. Asimismo, el análisis y la argumentación exploran de forma social e histórica el papel desempeñado por la ciudad en la llamada modernidad y el juicio crítico de la literatura frente a la condición humana y la vida que se desenvuelve en ella.

\section{Palabras clave}

Ciudad, cronotopo real, espacio de ficción, antropofajia, antropoemia.

\section{Abstract}

As the result of a brief study, this paper, contains an analysis of the novel Angosta (2003), by Colombian writer Héctor Abad Faciolince. In order to make the fictional space configuration possible in the novel, the author refers to social theory and sociocritical methodology. This paper establishes the relation between the historic chronotopos -in this case the contemporary city- and the axiological configuration of the fictional space used in the novel. Likewise, the analysis and the argumentation explore, sociologically and historically, the role played by the city in the so called modernity, and the critical judgment of literature regarding the human condition and the life it embraces.

\section{Keywords}

City, real chronotopos, fiction space, cannibalism, antropoemia.

Artículo recibido el 13 de septiembre de 2008 y aprobado el 28 de abril de 2009.

1 Especialista en formación de actores, ser. Licenciado en Filosofía y Letras, Universidad de la Salle. Magíster en Literatura Hispanoamericana, Instituto Caro y Cuervo. Profesor de Literatura Española e Hispanoamericana en la Universidad Pedagógica Nacional. Correo electrónico: palabreros@yahoo.com. 


\section{La ciudad como cronotopo real histórico}

No basta con vivir en la ciudad, si no se alcanza desde su mismo rechazo, si no se entra en ella por calles que no son las de los planos. Una ciudad es también fantasma que sólo la ingenuidad del habitante cree domesticable y próximo; apenas unos pocos saben del mecanismo interior que hace caer las fachadas y da acceso por oscuros paisajes a sus últimos reductos.

Julio Cortázar

La categoría de cronotopo fue planteada por Bajtín (1989) y se entiende como "la conexión esencial de relaciones temporales y espaciales asimiladas artísticamente" (p. 237), es decir, objetivada en las masas verbales y en cada uno de los elementos presentes en una obra literaria. Bajtín demuestra que:

La obra y el mundo representado en ella se incorporan al mundo real y lo enriquecen; y el mundo real se incorpora a la obra y al mundo representado en ella, tanto durante el proceso de elaboración de la misma, como en el posterior proceso de su vida, en la elaboración de la obra a través de la percepción creativa de los oyentes lectores (p. 404).

Es así como este trabajo explora esas dos dimensiones del cronotopo, tanto el real histórico, como el de ficción, que en una especie de círculo hermenéutico permiten hacer emerger el mundo objetivado y evaluado en la novela.

La novela es el género crítico de la modernidad, sentenció Lukács, y la modernidad se funda precisamente con la ciudad. En la antigüedad la ciudad inaugura la organización sistemática de la vida bajo el abrigo de la polis, ciudad estado, que obedece a principios políticos, económicos, religiosos o sociales que en adelante en mayor o menor grado se impondrán sobre la sociedad civil. El orden político de la ciudad, y he ahí la tragedia de Antígona²,

2 En la tragedia de Sófocles, Antígona se rehúsa a aceptar las leyes impuestas por Creonte frente a la muerte de los dos hermanos (Etéocles y Polinice). A Etéocles ha ordenado cumplir las honras fúnebres, mientras que a Polinice ha ordenado dejarlo insepulto. Antígona transgrede la norma argumentando que debe obedecer a los dioses de abajo y los lazos naturales (visión mítica) antes que a las leyes de la polis. Es a partir de esta radicalización del héroe como se configura su carácter trágico, pero también se evidencia supone el paso del mito al logos, es decir, de las creencias a las leyes.

Es en la época moderna, fortalecida con el pensamiento renacentista, cuando la modernidad como una mentalidad generalizada cobra suficiente vuelo para superar las verdades teocéntricas e implantar al hombre en el corazón del mundo; secularización, desmitificación del universo, confianza en la razón, evidencias de la ciencia, fortalecimiento del capitalismo, darán un vuelco trascendental a la forma de concebir el universo. La ciudad será a partir de entonces el gran centro urbano de acopio y transformación del orden social:

El centro hacia el cual gravita la sociedad medieval es la tierra, el suelo, pero en la época del Renacimiento se desplaza el centro económico y también el social, a la ciudad. Se pasa del polo "conservador" al "liberal", pues la ciudad representa el elemento movedizo y cambiante (Von Martin, 1996, p. 13).

Por primera vez, al menos para los estudios sociológicos contemporáneos, la ciudad, su espacio, representa una nueva concepción frente al mundo. Se trata nada más ni menos que de la intersección entre el espacio y una forma de ser en el mundo real, en la que el espacio interviene directamente en la transformación del sujeto. El hombre de la colectividad bajo la jerarquía medieval derrota el orden establecido y pasa al orden individual de la burguesía moderna; el hombre naturalizado por los designios divinos derrota a Dios para liberarse de sus sentencias. Los vínculos de comunidad, los sentimientos de grupo y de tradición van dando paso a un espíritu más urbano y liberal que pasa del valor de uso al valor de cambio hasta crear una mentalidad completamente nueva: calculadora, materialista, individualista y progresista.

En la ciudad van a concentrarse todos los poderes y todos los sujetos. Quizá el mojón que instaura a la ciudad como la gran cuna y fortalecimiento de la modernidad será la Revolución Industrial, que va a

la transformación del orden social en el tránsito del mito al logos que gobierna a la polis. 
cambiar rotundamente las relaciones sociales ${ }^{3}$, y que desde una perspectiva marxista producirá dos tipos de clases sociales burguesas: la burguesía industrial y el proletariado fabril. La Revolución Industrial, con el paso de los siglos, producirá grandes ciudades industriales que se impondrán como imagen de progreso, pero también de una mal entendida modernidad, pues de fondo los valores utópicos de la modernidad, alumbrados por la ilustración, quedarán despojados de realización.

Habitamos una ciudad, pero ella también habita en nosotros, todas sus estructuras forman parte de la realidad del sujeto, no habitamos por fuera de ella. La tradición moderna está signada por la heterogeneidad, la pluralidad de pasados, extrañeza radical, rupturas constantes en las que el hoy no es el hijo del ayer, sino su ruptura y su negación. Como dice Gadamer, "la modernidad es una época de abandono de una sociedad que descansa en sí misma y que es guiada por la tradición. Es el vuelco hacia aquella dinámica de desarrollo acelerado" (2004, p. 28). La identidad, la memoria, es decir, el relato del sujeto, se construye a partir de la constante innovación y destrucción del pasado inmediato.

La ciudad trasplantada al continente americano durante la conquista tendrá sus dinámicas particulares. Según lo ha estudiado José Luis Romero (1976), la ciudad no desempeñó el mismo papel en todas partes, lo cual marca un proceso heterogéneo. "La ciudad comenzó, la mayoría de las veces siendo un fuerte" (p. 38), no sólo para luchar contra la naturaleza, sino contra la hostilidad de los pueblos americanos y la disputa de los conquistadores por la posesión de ciertas regiones, como fue el caso,

3 El estudio que hace Mijailov (1978) al respecto sugiere que "el marxismo demostró que la humanidad pasó por cuatro formaciones: la primitiva, la esclavista, la feudal y la capitalista" (p. 6) y una quinta vendría a constituirla el socialismo-comunismo. El estudio de Mijailov se orienta desde la perspectiva del marxismo ortodoxo que confiere una fijación casi absoluta en la superestructura económica realizada en la tenencia de los medios de producción y sus corolarios (proletariado, plusvalía, cosificación, enajenación, alienación). El estudio sobre la revolución industrial, libro clásico de Mijailov, constituye una crítica marxista a la modernidad, intenta desmontar la falsedad de las ideologías burguesas acerca de la eternidad y la inmutabilidad de los regímenes capitalistas así como la falsedad que confiere al Estado burgués la generación del bienestar general. según lo señala Romero, de Veracruz, Río de Janeiro y Arrecife.

En el estudio de Romero, la ciudad otras veces "comenzó como puerto de enlace, cuyas funciones de bastión mercantil se complementaron en algunos casos con las de mercado, convirtiéndola en una ciudad-emporio" (p. 40), este es el caso de ciudades como San Juan de Puerto Rico, Panamá, Santiago de Cuba, La Habana; y cuando estas ciudades fueron destruidas, entonces se amurallaron y se les dio un castillo o un morro, como en el caso de Cartagena. Otras veces, la ciudad fue originariamente un punto de etapa, un centro de reagrupamiento de personas y cosas para asegurar la prosecución de la marcha hacia regiones lejanas o peligrosas" (p. 42 ). (Puebla, en México, y La Rioja, en Argentina); casi siempre la ciudad europea fue levantada sobre el lugar de una ciudad indígena, como en los casos de México, Cuzco y Cholula, Bogotá, Mendoza y San Pablo, en Brasil. Un último sentido de la ciudad fundada por los españoles y portugueses tendrá que ver con la actividad minera, como en el caso de Taxo y Guanajuato en México, Villa Rica en Brasil y Potosí en Perú.

En términos generales, y pese a las funciones iniciales, la ciudad tendrá patrimonios comunes que van a marcar el designio de las sociedades que se establecerán tras el choque cultural entre Europa y el nuevo mundo. Señala Romero que "Latinoamérica se había construido a partir del siglo XVI como una proyección del mundo europeo" (p.XXI); las ciudades aseguraron la presencia de la cultura europea, dirigieron el proceso económico y, sobre todo, trazaron el perfil de las regiones sobre las que ejercerían su influencia:

El aniquilamiento de las viejas culturas-primitivas o desarrolladas y la deliberada ignorancia de su significación constituía el paso imprescindible para el designio fundamental de la conquista: instalar sobre una naturaleza vacía una nueva Europa, a cuyos montes, ríos y provincias ordenaba una real cédula que les pusieran nombres como si nunca los hubieran tenido (Romero, 1999, p. XXV). 
España pudo lograr su conquista gracias a la instauración de una red de ciudades que en menos de un siglo le permitió tener el dominio y control del basto territorio americano; instauró con la ciudad un orden jerárquico preestablecido, abolió las formas orgánicas de las culturas prehispánicas; trazó ciudades remedo de sus ciudades españolas e instauró la continuación de un orden mental.

El orden mental, las categorías del pensamiento son las que pueden relacionarse con el segundo término del cronotopo, el tiempo, entendido como la significación histórica de los valores que encarna una cultura. Néstor García Canclini (1990) llega a la conclusión que:

Fuimos colonizados por las naciones europeas más atrasadas, sometidos a la contrarreforma y otros movimientos antimodernos, sólo con la independencia pudimos iniciar la actualización de nuestros países. Desde entonces hubo olas de modernización (p. 65).

La modernización puede entenderse como el proceso de construcción de herramientas y métodos puestos al servicio del progreso de la sociedad, sin que ello implique los saltos cualitativos en el pensamiento moderno. En general, el pensamiento político en América Latina ha estado inspirado por el pensamiento cristiano, con pocos giros e intentos por secularizar los Estados.

La ciudad latinoamericana como cronotopo real histórico en su relato inicia su movimiento argumental con los actos simbólicos de las fundaciones que aniquilan cualquier consideración del hombre cultural propio para instaurar un nuevo orden social; continúa con el surgimiento de papeles sociales durante la colonia: encomenderos, señores, castas reales, criollos marginales, aborígenes y negros esclavos. El movimiento del tiempo argumental, asumiendo la ciudad como el relato histórico real, iniciará un tercer momento de conclusión con los procesos de independencia, durante los cuales los pueblos latinoamericanos intentarán instaurar una identidad y una autonomía. Sin embargo, este esbozo de movimiento temporal no debe considerarse como algo continuo, uniforme, estable, casi aristo- télico. Por el contrario, el movimiento del tiempo ha sido más bien imprevisto, comenzado por el inesperado choque de culturas en 1492, inestable como ha demostrado la tarea ardua de conformar repúblicas independientes que todavía hoy, al inicio del siglo XXI, no terminan de organizarse, de entenderse, de legitimarse como naciones independientes, sino que parecen especies de veletas movidas y orientadas por el constante flujo del mundo capitalista, por políticas dominantes internacionales y por los caprichos de gobernantes autoritarios. Naciones que, como relato, son plataformas de neocolonialismos, identidades fragmentadas e ilusorias, fronteras abiertas al mundo, autonomías quebradizas y fluctuantes.

En la marcha de la ciudad como cronotopo real histórico, hay un fenómeno que interesa para comprender su importancia: la ciudad letrada. La polis pronto encontrará en los intelectuales letrados un instrumento para legitimar su poder, es decir, para argumentar la organización sistemática de la vida. El cronotopo real histórico estará atravesado por varios ejes como: el político, el arquitectónico, el social, el económico, religioso, afectivo, entre otros. Esa es la complejidad propia de la ciudad. Sustancialmente, el tiempo y el espacio son inseparables. Allí donde se formula una jerarquía se establece una especialidad particular, pero todo ello encontrará en la ciudad escrituraria la legitimación del orden de la polis. Es Ángel Rama (1984) quien señala cómo la ciudad letrada por medio del orden de los signos articuló su relación con el poder "al que sirvió mediante leyes, reglamentos, proclamas, cédulas, propaganda, y mediante la ideologización destinada a sustentarlo y a justificarlo" (p. 41). Tres elementos básicos distinguen la ciudad letrada: concentración, elitismos, y jerarquización. Estas tres formas de asumir la ciudad distancian la población rural de la urbe, la palabra escrita de la hablada, la palabra culta de la del vulgo, la opinión de la norma. La ciudad escrituraria pertenecerá sólo a una minoría que ostentará su pluma junto al poder, concentrará los poderes y dictará la norma cultural. Es decir, el proyecto de nación a seguir, la literatura a escribir, la conducta a obedecer, los lugares para vivir. 
La ciudad, a medida que avanzaron los procesos de modernización, serviría de escenario a los procesos de industrialización que, en el caso de Latinoamérica, se han malentendido como modernidad. La modernidad implicaría una nueva mentalidad, cierta lucha por instaurarse en el logos y dejar de lado el mito, y no como afirma Fernando Cruz Kronfly, haber confundido modernización con modernidad:

Hasta los comienzos del siglo XX, casi todo el país se podía definir como material y espiritualmente premoderno. Únicamente estaban al día dos o tres empresarios y cuatro o cinco intelectuales que lograban viajar a Europa. En tales condiciones, nuestro atraso económico no era capaz de generar mayores conflictos, puesto que las grandes masas campesinas, porcentualmente mayoritarias, no dejaban de ver su situación de marginalidad como consecuencias del destino (1994, p. 13).

Lo anterior ilustra la asimilación que para la época se tenía de la historia, es decir, la axiología, los valores que encarna la sociedad. Si se piensan bien las cosas, hasta el pensamiento moderno de Marx pasaba tangencialmente y la ideología católica refirmaba el atraso y convertía el dolor, la pobreza, la miseria en promesa divina de bienaventuranza. Una falacia ideológica que ha estado presente, hasta hoy, en el pensamiento premoderno del Estado colombiano. En ese sentido, el pensamiento premoderno de la iglesia católica ha servido y contribuido a legitimar las diferencias económicas al no optar por un camino crítico de la políticas nacionales, sino de paliativo y justificación de las circunstancias como consecuencia de un designio divino.

El primer término del cronotopo real histórico, en el caso colombiano, es una imposibilidad si se piensa en relación con una concepción generalizada de modernidad. Más bien, la marcha histórica del cronotopo real hay que pensarla como lo ha entendido Cruz Kronfly (1998), como un "hibridaje cultural de temporalidades históricas en América Latina". Se define como "simultaneidad de las diferentes dimensiones del tiempo en la cultura. Dicho de otro modo parecería como si fuéramos premodernos, modernos y posmodernos al mismo tiempo" (p. 15). Esta simultaneidad, señala Cruz Kronfly, se ha convertido en una especie de señal o característica cultural de América Latina: mixtura, hibridaje, simultaneidad. El sujeto latinoamericano estaría capacitado para incorporar e interiorizar sin contradicción interior, elementos, representaciones, valores, sensibilidades, objetos culturales provenientes de diferentes temporalidades y espacialidades. En síntesis, el sujeto latinoamericano "es una especie de suma histórica sin eliminaciones" (p. 17).

Si la concepción del primer término del cronotopo puede entenderse en ese sentido de sumas de temporalidades, de igual manera puede entenderse el topo, segundo término del cronotopo real histórico. La ciudad es una mixtura de todos los procesos sufridos larguen el trasncurso de la historia. La ciudad guarda en su arquitectura, en sus organizaciones sociales, en las políticas que la cobijan, los rezagos históricos e ideológicos bajo los cuales se ha configurado. La arquitectura de la ciudad, por ejemplo, en el paisaje sensible que se ofrece a sus habitantes o a sus visitantes, ofrece sus propios signos, que bien pueden leerse de la siguiente forma:

El paisaje urbano aparece como una yuxtaposición de artefactos efímeros con restos de infraestructura obsoleta, tejido decadente, fábricas abandonadas, enormes vacíos, viviendas precarias en los intersticios y de pronto como enclaves autosuficientes, incrustaciones radiantes de novedad técnica o social, con la trama invisible pero omnipresente de los medios electrónicos configurando nuevos recorridos, nuevas fruiciones; la ciudad es definitivamente ya un patchwork en el que cada fragmento libera su sentido, pero en esa libertad no predomina la diferencia, sino el contraste y la desigualdad. Esa es la modernización actual, post-expansiva, cuya mezcla de tiempos replica la lectura actual de la ciudad como ruina de la modernidad (Universitas Humanista, 2003, pp. 11-27).Número de la revista

La novela Angosta, en su asimilación artística del cronotopo, es un poco la creación posible, el cronotopo representado de esas ciudades múltiples, heterogéneas, invisibles, yuxtapuestas, escindidas, voraces para la vida que su autor ha condensado en cada una de sus líneas. 


\section{El acontecimiento en la novela Angosta}

Bajtín ha planteado tres elementos importantes que le confieren el carácter central al cronotopo en la novela: unidad artística, importancia temática e importancia figurativa. El primer aspecto permite al crítico determinar la mirada particular que hace el escritor sobre la realidad en la novela, la toma de posición frente a la historia. El segundo aspecto es el que permite entrar en los tejidos internos de la novela para analizar cómo se enlazan y desenlazan los nudos argumentales, el punto de partida argumental y el punto de conclusión del mismo. La importancia figurativa se evidenciará en los procedimientos y elementos de los que dispone el narrador: describir, narrar, contar, comentar, entre otros, objetivados en las masas verbales, y que finalmente permiten configurar el espacio de ficción presente en la novela.

En la novela Angosta, el punto de partida argumental se inicia con la lectura que realiza el personaje central, Jacobo Lince, de un atlas que describe las características de la ciudad de Angosta. Este es el momento inicial del cronotopo. El punto de conclusión del movimiento argumental se dará cuando el personaje se exilia de dicha ciudad. Entre estos dos puntos suceden los demás nodos argumentales que organizan la novela. Los pequeños nodos argumentales se comprenden a partir de la escisión espacial de la ciudad: Angosta es una ciudad dividida en "sektores", que son espacios físicos, pero que son, a su vez, límites sociales: Paradiso, Sector $\mathrm{T}$ y el Sector C. La pertenencia y la movilidad de un lugar a otro dependerá de la capacidad económica de los habitantes y de los permisos de los Dones, gobernantes de Angosta, para pasar el Check point, punto de control, o muro que divide a Paradiso de los otros "sektores".

Jacobo Lince posee un millón de dólares, heredado de su madre, condición que le permitiría vivir en Paradiso, pero que él ha rechazado para no sumarse a la moral impuesta, y prefiere vivir en el Hotel La Comedia, ubicado en Tierra Templada (Sector T). Además, Jacobo Lince es separado de su esposa, mujer de la casta de los Dones, tiene una pequeña hija con ella, se ha hecho la vasectomía como una negación a la proliferación de la vida en un mundo donde el protagonista ha perdido la creencia en el amor y la institucionalidad de la familia, que es asumida como una empresa más y bajo connotaciones morales como la monogamia, que el personaje no está dispuesto a seguir. Jacobo Lince es dueño de la Librería La Cuña y su movilidad en Angosta estará legitimada por su posibilidad económica, su interés por salir del aburrimiento y la búsqueda de aventura y mujeres para satisfacer sus necesidades sexuales.

Frente a la movilidad de Jacobo Lince, que puede desplazarse como un turista por toda la ciudad, emergen otros personajes, que, pese a las restricciones sociales impuestas por la política del apartheid, buscan y pretenden integrarse a las otras esferas sociales. Uno de ellos será Andrés Zuleta, un joven de veinticinco años que ha abandonado su casa paterna e intenta trabajar en el Paradiso con la Fundación $\mathrm{H}$, que trabaja por los Derechos Humanos en la malograda Angosta. El segundo personaje en esta categoría será Virginia Buendía, alias Candela, una desplazada, irónicamente, del realismo mágico de Macondo, y que pertenece a Tierra Caliente, ella, gracias a los contactos con el hampa, intenta conseguir un pasaporte para ingresar a Paradiso. Los dos, a partir de circunstancias violentas, terminarán viviendo en el Hotel La Comedia y van a comprometer al héroe moral y afectivamente.

En la librería La Cuña, Jacobo Lince conoce a una mujer, la segunda en importancia para el argumento de la novela, Camila Restrepo, una estudiante de comunicación social, que realiza un estudio sobre Angosta. Ella está interesada en el atlas que estaba leyendo Jacobo Lince al inicio del acontecimiento. A partir de este personaje, se objetivarán otras problemáticas de la realidad de Angosta, se completa el sistema de personajes en la novela y se establecen las relaciones que hacen complejo el argumento. Camila Restrepo es propiedad privada, por decirlo de una manera, es un objeto de deseo del Cacique Nutibara, un hombre de apuestas, con nexos en el narcotráfico y los grupos paramilitares de la Secur. El primer encuentro con Camila y el inmediato cortejo por parte de Jacobo Lince traerán como consecuencia una golpiza por parte de los guardaespaldas que vigilan a Camila Restrepo. Jacobo Lince 
queda malogrado tras la golpiza y en ese estado deplorable lo encontrará Andrés Zuleta. Será el joven el encargado de salvar al héroe y llevarlo hasta el Hotel La Comedia.

Jacobo, el personaje de la movilidad, el turista en la ciudad de barbarie, el náufrago de una vida malograda para la felicidad, emprenderá un viaje cuesta abajo, una especie de catábasis. Se trata de su descenso al espacio de los vomitados sociales, el lugar de los "terroristas" y el mundo del hampa: Tierra Caliente. Su intención inicial es salir del "aburrimiento" y decide ir a comer a un restaurante chino que queda cruzando el río Turbio, en el límite de Tierra Caliente, pero al tratar de avanzar por la Cuesta de Virgilio se pierde entre casas, calles y escaleras que no conducen a ningún lado. En ese infierno, Jacobo se desespera, entonces aparece Virginia Buendía, una muchacha de pelo rojo, quien lo pondrá a salvo, un guiño intertextual, la versión femenina de Virgilio ${ }^{4}$, símbolo de la poesía y la sabiduría en la Divina Comedia, pero más significativo si se interpreta como la presencia del amor como elemento salvador del infierno (Angosta). Con la aparición de Virginia Buendía, alias Candela, el héroe sufre una leve transformación al sentir que nuevamente se ha enamorado, así que decide llevarla a vivir al Hotel La Comedia.

Virginia Buendía se convierte en un personaje mediador entre los dos personajes centrales, es decir, entre Jacobo Lince y Andrés Zuleta, pues, el segundo quedará obnubilado con esta belleza rescatada del infierno. Para Jacobo Lince resurge una nueva posibilidad frente al amor, pues siempre ha tratado de encontrar a una mujer para amar de verdad; para Andrés Zuleta, sus ilusiones de encontrar una mujer con quien despachar por siempre su soledad parecen hacerse realidad.

Los personajes rescatados de los espacios émicos (vomitados sociales) parecen finalmente haber

4 También una mirada paródica a la familia patricia del real maravilloso en Cien años de soledad. Aquí los personajes de Macondo han sido desplazados a un mundo real donde sufren las consecuencias. Es decir, Virginia Buendía, una desplazada de Macondo, es la herencia de las luchas intestinas que dieron origen a nuestra sociedad y que heredaron su sangre y su desgracia. alcanzado parte de su metas: Andrés Zuleta ha encontrado trabajo en la Fundación $\mathrm{H}$, que dirige el profesor Burgos, y Jacobo Lince le ha conseguido trabajo en la Librería El Carnero a Virginia Buendía. Sin embargo, un acontecimiento cambiará el destino final de los personajes. Andrés Zuleta ha sido encargado de realizar un estudio sobre los desaparecidos en Angosta. Se trata de tomar fotografías de las torturas y homicidios que cometen los paramilitares de la Secur. Para hacer su trabajo, Jacobo Lince le presenta a su amiga Camila Restrepo para que le colabore tomando las fotografías. Los dos deciden encontrarse una tarde para ubicarse en un hotel adyacente al Salto de los Desesperados y poder tomar las fotos sin ser vistos.

En la antesala a la muerte, Camila seduce a Andrés Zuleta y con ella perderá su virginidad; luego llegan los hombres paramilitares para torturar a los señalados por la Secur; Camila inicia su trabajo, pero son delatados por el flash de la cámara. Los guardaespaldas de Camila la descubren y arrojan a Andrés Zuleta por el salto, no sin que antes Camila haya logrado esconder unos rollos entre las tablas. Tras este hecho macabro para la vida, Jacobo, junto con sus amigos, publica la noticia y las imágenes de las actividades de los hombres encubiertos del Estado, los paramilitares.

Tras la revelación de la verdad en la ciudad de las mentiras, Angosta, se inicia la persecución por parte del Estado y de los Paramilitares, que, para el caso colombiano, son lo mismo. Se persigue la Fundación $\mathrm{H}$ y se quema la Librería La Cuña, propiedad de Jacobo Lince, hecho que obliga al personaje a abandonar la ciudad para exiliarse en Argentina. Jacobo Lince abandona el país acompañado de Virginia Buendía. En el avión, Virginia mira imágenes de Andrés Zuleta como la evidencia de su amor frustrado, mientras Jacobo Lince vuelve los ojos al atlas del profesor Heinrich V. Guhl para leer nuevamente el enunciado que evalúa el cronotopo: "La capital de este curioso lugar de la tierra se llama Angosta. Salvo el clima, que es perfecto, todo en Angosta está mal. Podría ser el paraíso, pero se ha convertido en un infierno" (p. 372). 


\section{El espacio de ficción en la novela Angosta}

De la macondiana "aldea de veinte casas de barro y cañabrava construidas a la orilla de un río de aguas diáfanas" (García M., 2007, p. 9), se arriba a la convulsionada ciudad ${ }^{5}$ contemporánea de Angosta, que se desparrama a orillas de un río que llaman el Turbio y, pese a compartir con Macondo su nombre ficcional y su falta de referente extratextual, nada impide relacionarla con cualquier ciudad del mundo actual. En Angosta las cosas ya no son tan recientes, ya no hay que señalarlas con el dedo, y si alguna vez se señala es sólo para signar su barbarie y su mundo degradado.

\section{Espacio descrito, narrado y comentado}

En su forma composicional, la novela intercala tres relatos que focalizan la ciudad y la experiencia en ella. Un primer relato lo constituye la inclusión de un "breve tratado de geografía sobre Angosta" (p. 12), cuyo autor es el catedrático alemán Heinrich V. Guhl. El segundo relato se construye a partir de la mirada y vivencia del joven Andrés Zuleta, titulado "Cuaderno de Andrés Zuleta". El tercer relato está construido por un narrador omnisciente que organiza los dos anteriores y crea la unidad total de la narración. De esta manera, las tres miradas configuran una misma evaluación del espacio en Angosta que puede sintetizarse así: Angosta ya no es la arcadia, sino el paraíso perdido, es decir, un infierno.

La reflexión de Teresa Zubiaurre respecto al espacio en la novela realista permite introducir el desempeño del narrador en relación con la configuración del espacio de ficción en la novela Angosta:

Toda escritura fictiva encierra tres disfrutes: narrar, dialogar y describir (y aún queda un cuarto, comentar) [...] Narrar no es otra cosa que observar la realidad en movimiento; describir es asombrarse ante la inmovilidad de las cosas, ante ese universo que va a durar mucho más que nosotros; dialogar, por fin es comprobar la presencia de

5 En cuanto estudios colombianos y críticas del tópico de la ciudad en la literatura colombiana puede consultarse: Giraldo, Luz Mery, 2000. También un ensayo de Fernando Cruz Kronfly titulado "Las ciudades literarias" En Revista Universidad del Valle, 14. los otros, aceptación reconfortante de un destino común (2000, pp. 45-46).

Partiendo de estas definiciones, es posible observar cómo, a partir de la descripción, la narración o el diálogo, se hace emerger el espacio. El espacio no será, entonces, un mero escenario donde sucede la acción, sino el elemento necesario para la configuración de una mirada crítica sobre el polvorín social que se sucede en él.

\section{La descripción sobre Angosta}

Es por medio del breve tratado de geografía sobre Angosta $^{6}$ como se reconstruyen el pasado y presente de la ciudad. El tratado tiene carácter científico y pretende describir el espacio geográfico y social de la ciudad. En él se delimita el espacio geográfico de Angosta que va desde "el océano Pacífico hasta el río Orinoco, y desde el río Amazonas hasta el mar de las Antillas. Allí la cordillera de los Andes, agotada..." (p. 12). A partir de este relato se hace un inventario minucioso de los elementos presentes en Angosta: el clima, la vegetación, la orografía, es decir, literariamente se construye una topografía de la totalidad donde sucede la acción y se desarrolla la historia.

Por ser este un género extraliterario y científico, el punto de vista intenta mayor objetividad, pero sin lograrlo del todo, pues pronto la subjetividad se deja entrever en la construcción de la mirada oponiendo dos sentidos: maravilla vs. barbarie:

La capital de este curioso lugar de la tierra se llama Angosta. Salvo el clima que es perfecto, todo en Angosta está mal. Podría ser el paraíso, pero se ha convertido en un infierno. Sus habitantes viven en un lugar único y privilegiado, pero no se dan cuenta ni lo cuidan [...]. Hoy todo el territorio está

6 El tratado está adjudicado al catedrático alemán Heinrich V. Guhl. Ciertamente, el profesor Guhl es un personaje de la vida real, pero ficcionalizado en la novela. Guhl trabajó en la Universidad Nacional de Colombia como profesor de geografía e investigador. Sin embargo, la intertextualidad más fuerte la presenta con la obra Vistas de las cordilleras de Alexander Von Humboldt, no sólo por el tono descriptivo y narrativo, sino por la estructura y los elementos de que se ocupa: la cordillera, la ciudad, el salto de Tequendama. Véase Humboldt, 2005. 
ocupado por una metrópoli de calles abigarradas, altos edificios, fábricas, centros comerciales y miles de casitas de color ladrillo que se encaraman por las laderas de las montañas (p.14)

Con la descripción se inicia la configuración del espacio de la ficción. La ciudad aparece como la totalidad del espacio ficcional. Angosta viene a ser el nombre y la identificación más simple de la descripción. "Nombrar es conjurar. De todos los elementos lingüísticos que se reúnen para crear una ilusión de realidad, el nombre propio es quizá el de más alto valor referencial" (Pimentel, 2001, p. 29). Con él se crea la ilusión de un referente extratextual que, para este caso o para el de Macondo, no existe. Sin embargo, los elementos de la descripción, los detalles, la ubicación geográfica, su historia permiten poner a Angosta en relación con los procesos históricos de la ciudad latinoamericana.

Este primer relato intercalado en la novela aportará las conexiones con la historia de las urbes latinoamericanas7: "los fundadores de la ciudad eran españoles, casi todos: vascos, extremeños, andaluces o castellanos, pero también judíos conversos y moriscos vergonzantes" (Abad, 2003, p. 18). A partir de esta historia social, quedan enumerados los orígenes de las ciudades y las castas sociales de Angosta que guardan estrecha relación con la historia de América Latina: dones, segundones y tercerones. A su vez,

7 José Luis Romero (1999) aporta en su estudio Latinoamérica: las ciudades y las ideas un análisis desde la historia social de la manera en que se configuraron las ciudades y las sociedades urbanas. Romero caracteriza los grupos originarios urbanos como gente de condición humilde pero aventurera, codiciosa y dispuesta a prosperar. "América fue, en efecto, una oportunidad para los que buscaban el ascenso económico y social" (p. 53). "El éxito en tierra americana consistía para el nuevo poblador en alcanzar una posición social análoga a la de los hidalgos peninsulares, posición a la que debía servir de fundamento la riqueza fácilmente adquirida" ( $p$. 53). La fundación de las ciudades en América más que fundar una ciudad fundó un prototipo de sociedad que fue reelaborándose a medida que las ciudades latinoamericanas cobraban autonomía y se sumaban a los procesos de industrialización que el mundo iba imponiendo. Así la ciudad, en líneas generales, pasa por la ciudad hidalga, que se funda sobre el desconocimiento general de las ciudades indígenas. Esta ciudad hidalga se fundará sobre patrones y funciones preestablecidas. Luego la ciudad y las relaciones sociales darán paso a la ciudad patricia, que ya incluye más elementos de identidad y pensamiento autónomo y finalmente se llegará a la ciudad burguesa, que antecede a la masificada. estas castas sociales tendrán legitimados lugares en la división espacial de Angosta:

Entre sus descendientes, mestizos y mulatos como todos, aunque con pretensiones de hidalgos, por lo ricos, a los que menos mal les fue, la costumbre les concedió el título de dones, y se mudaron a vivir a Tierra Fría, en la azotea de Angosta, un altiplano grande y fértil al que le dicen Paradiso. En el valle estrecho de la Tierra Templada, donde existía una encomienda de los indios mansos, o al menos los amansados, se quedaron los segundones, casta intermedia que se debate entre el miedo a que los confundan con los tercerones y la ambición de merecer algún día el título de don (p. 18).

Los espacios en sí no emergen de forma natural, sino que son producto de concepciones de mundo. Para Yury Lotman, por ejemplo, "los modelos históricos y lingüísticos nacionales del espacio se convierten en la base organizadora para la construcción de una imagen del mundo, un modelo ideológico global propio de un tipo de cultura dado" (1997, p. 272). El modelo de mundo organizador de la sociedad como correlato en el texto ficcional de Angosta se evidenciará, o puede estudiarse, a partir de las siguientes polaridades:

Arriba-abajo: se trata de una relación de tipo vertical que de paso conecta intertextualmente con la Divina Comedia de Dante Alighieri. Arriba en la azotea geográfica queda el Sector F, Tierra Fría, llamado también Paradiso. Abajo queda el Sector Co Tierra Caliente, nombrado como el Infierno. Éste se inicia con el Salto de los Desesperados, cuya base es llamada la "Boca del Infierno". Este abismo, cargado de fuerza por las aguas del Turbio, fue en el pasado un lugar romántico para los suicidas, pero ahora es sólo un botadero de muertos. Producto de las masacres de la Secur (grupo paramilitar-asesino). En la mitad está Tierra Templada, que sirve de tránsito entre los dos sectores y en el cual viven la mayoría de los personajes de la novela.

Ricos-pobres: aparentemente lo que existe en Angosta es una tríada social establecida como dones, segundones y tercerones, pero en síntesis se trata más bien de una polaridad entre ricos y pobres. Aunque la polaridad rico-pobre sea de carácter sociológico, 
resulta derivada de la dualidad arriba-abajo. Esto se explica a partir de la división de Angosta a través de un muro y un punto de control, el Check Point, que sirve para restringir la movilidad de sus habitantes. Esta polaridad simbólicamente representa a los países del primer mundo frente a los del tercero. Los primeros quedarán descritos como: "poca gente, ambiente limpio, brillante, con pocos pobres, sin mendigos, lleno de casas, amplias y resplandecientes. [...] El único peligro son los atentados" (p. 29). En contraste con la especialidad del primer mundo, el espacio del tercero queda descrito de la siguiente manera: "hay basura, cáscaras, papeles en el suelo. [...] En las esquinas empiezan a verse facinerosos con cara de buenos amigos [...]. Hay mendigos acuclillados en los rincones, cada vez más mendigos que piden con gestos perentorios y agresivos [...]" (p. 28). Estas dos descripciones enfrentan la polaridad espacial y sustancial en la novela y conectan su imagen con la imagen del mundo actual escindido por las relaciones capitalistas. En la novela, esta relación con el dinero quedará explícitamente desarrollada, pues es necesario poseer un millón de dólares para poder vivir en Paradiso.

Al observar la focalización en el espacio, se pueden afirmar dos cosas. Primero, que el espacio físico está directamente relacionado con el poder económico y adquisitivo del que se disponga para vivir en Angosta y, segundo, que de esa relación emerge a su vez el espacio social8 angosteño. El espacio social quedará delimitado por lo que en Angosta los Dones llaman la política del Apartheid, que se hace evidente con la presencia del muro, el Check Point y los grupos de control que ejercen el orden bajo tácticas paramilitares. Es decir, la ejecución de la barbarie. Así, el espacio queda delimitado entre los que poseen "un millón de dólares" para poder vivir en el

8 Bauman (2004, p. 166) opone dialécticamente la noción de "espacio social" (no objetivo) a la de "espacio como tal" (físico, puro), esto le permite establecer relaciones de proximidad y distancia, cercanía y de apertura. En su reflexión, tanto lo cognitivo, como lo estético y lo moral son mecanismos que permiten la producción del espacio: "el espacio cognitivo se construye intelectualmente, por la adquisición y distribución del conocimiento; el espacio estético se mapea afectivamente por la intención guiada por la curiosidad; [...] el espacio moral, a su vez, se construye mediante una distribución desigual de responsabilidad sentida/asumida". primer mundo y aquellos que no lo poseen. Mientras para unos el goce estético de la ciudad queda asegurado, para los otros la posibilidad de gozar de una ciudad limpia, con cines, amplias zonas verdes y cultura queda restringida. Lo urbano emerge como problema central en la novela y cuestiona los límites que restringen lo público de lo privado. El espacio público apto para el goce estético es restringido y queda destinado al sector de la exclusividad.

Angosta es una ciudad donde se crea la falsa idea de identidad comunitaria, que tiene como fin último preservar el orden mediante el control de los espacios. Como estudia Bauman (2006), la "defensa de la comunidad", que se resume en la política del Apartheid de Angosta, evidencia la escisión actual de la vida urbana:

Contratación de guardianes armados para cuestionar la entrada; los merodeadores y vagabundos promovidos al rango de enemigos públicos número uno; el recorte de la áreas públicas a los enclaves "definibles" de acceso selectivo; la separación y la no negociación de la vida en común y la criminalización de las diferencias residuales (p. 102).

Adentro-afuera: esta relación resulta interesante desde el punto de vista de Andrés Zuleta, otro de los personajes centrales. El adentro está representado por la casa y el afuera por la ciudad. Semánticamente conduce a la relación asfixia-libertad, y también a las marcas de lo privado y lo público. En Angosta, el espacio privado, el espacio íntimo de la casa, no es el lugar del refugio, como imaginaba Bachelard: "Antes de ser lanzado al mundo, como dicen los metafísicos rápidos, el hombre es depositado en la cuna de la casa. Y siempre, en nuestros sueños, la casa es una gran cuna" (1993, p. 36). Esta definición de Bachelard va en el sentido de lo que Bajtín ha denominado cronotopo del idilio familiar, pero en la novela Angosta se trata de su ruptura. En el recuerdo de Andrés Zuleta, el espacio de la casa no es el lugar de la ensoñación; su casa representa el primer territorio de hostilidades, es el espacio del odio, de la destrucción de la familia. Allí su padre, su madre y su hermano lo detestan por no sumarse a la moral impuesta, por no elegir una carrera "útil" 
para la sociedad. La utilidad sólo será pensada en términos de producción para el mercado. Este personaje, por el contrario, ha pensado en ser poeta $y$ escritor, hecho que genera la discordia.

Para Andrés Zuleta, la libertad está afuera, en la ciudad, sin embargo, la ciudad sólo puede ofrecerle un espacio degradado y jerarquizado. El espacio de lo público, de la libertad resulta igualmente asfixiante, aunque mejor: "cuando salí, creo que respiré con libertad por primera vez en varios años. Era una sensación casi olvidada, como de último día de colegio [...]" (p. 69). Este contraste se expresa en dos sentidos, en cuanto la tensión familiar es generada por dos visiones de mundo contrarias y por la descripción del espacio de la casa. Este es un espacio que ha sido invadido por los medios de comunicación y toda su telebasura. La casa se asemeja más a un microcosmos de la ciudad entera, a una especie de basurero de las relaciones sociales y la producción en masa:

Para no lavar muy a menudo, hay cientos de platos y cientos de cubiertos. En el mismo lavadero está la bolsa con la basura, y ahí se mezclan y se huelen sobrados de comida, cáscaras de frutas, cortezas de queso, restos de arroz y frisoles (p.162).

La casa se vuelve otro lugar asfixiante, en una imagen simbólica del mundo contemporáneo, ya no es la cuna que acoge, sino el lugar que arroja, porque la visión de mundo de Andrés Zuleta no puede acomodarse a ella, esa acción inicia su configuración como héroe problemático, no se adapta al mundo y tiene que iniciar su búsqueda arrojándose al mundo en busca de la libertad.

La relación adentro-afuera también se verá reproducida en el orden de la ciudad. Estar adentro, en el Paradiso, garantiza estabilidad, cierta oportunidad para sobrevivir, estar afuera implica estar en la tangente de las oportunidades mínimas de trabajo. Jacobo Lince puede estar en Paradiso porque tiene el dinero para lograrlo, pero su configuración como héroe problemático no le permite sumarse a la moral burguesa y prefiere acomodarse afuera, ir de un lado a otro, deambular por la ciudad, vivir como si fuera posible no excluir a los otros.

\section{El espacio narrado en Angosta}

Inmersos en el espacio escindido y degradado de la ciudad, irrumpen los personajes de la novela. Aquí ya no la descripción, sino la narración de las acciones y los acontecimientos cobra importancia en la emergencia del espacio físico y social de Angosta. Los personajes tendrán que moverse siempre en espacios peligrosos, asediados y censurados por el grupo paramilitar que controla la movilidad, el desorden, la expresión y el derecho a la verdad: la Secur.

La novela inicia narrando las acciones de Jacobo Lince. Jacobo es dueño de la Librería La Cuña y ha llevado un libro para leer en su casa. Se trata del breve tratado de geografía. Así, la novela inicia estableciendo dos planos en la narración. Por un lado, la narración de Guhl, que desde su presente describe la ciudad y la compara con el pasado y, por otro, el personaje que intenta contrastar el pasado con su presente y que, a su vez, es observado por un narrador omnisciente muy cercano a él:

Trata de calcular desde donde habrán visto los conquistadores el valle de Angosta, y cómo habrá sido antes su apariencia, sin edificios, sin casas, sin ruido. [...] Él mismo no lo sabe, pero cuando abre el libro y se sumerge en las palabras, es una persona feliz, ausente de este mundo, embebida en algo que aunque habla de su ciudad, sino otra cosa mejor y más manejable, unas palabras que intentan representarla (p. 15).

De esta manera, la aparente realidad ostensible que pretende el tratado de Guhl es tomado por segunda vez en el plano ficcional. Ahora el referente de su relato pasa a ser un mundo creado. El mundo descrito allí se convierte para el personaje en un mundo posible, al punto que su imaginación y su ensoñación le hacen perder el contacto con la realidad. El mundo descrito ha permitido crear una especie de marco donde los espacios resultan polarizados, divididos y jerarquizados. Es bajo esa complejidad espacial como el argumento y las acciones de los personajes cobran sentido y, al mismo tiempo, el espacio se intensifica y se restituye como nivel privilegiado. 
Pareciera que el espacio sólo puede ser descrito y no narrado, pero la movilidad es una categoría espacial. Moverse implica una orientación y una acción espacio temporal. Jacobo Lince es un personaje que vive en el Hotel La Comedia y puede desplazarse por toda la ciudad. En contraste con la movilidad de Jacobo Lince, los demás personajes deben poseer un pasaporte otorgado por los Dones. Jacobo Lince podría vivir en Paradiso, pues posee un millón de dólares, y sin embargo prefiere hacerlo en el Hotel La Comedia. Esta actitud lo configura como héroe problemático. Su elección lo convierte en un héroe lúcido, capaz de no plegarse al imaginario de exclusividad de quienes habitan en Paradiso. Sin embargo, el espacio del Hotel La Comedia viene a reproducir la estructura social imperante en Angosta. Una vez más, la novela se relaciona con la especialidad geométrica presente en la Divina Comedia de Dante. Si en el Infierno de Dante hay nueve círculos, en el Hotel La Comedia hay nueve pisos. Los círculos representan el lugar donde castigan a los pecadores condenados. En el hotel la Comedia, cada piso es símbolo de la condena social. Si en la Divina Comedia el descenso va de acuerdo con el nivel de los pecados, en el Hotel La Comedia sucede a la inversa, la condena va en ascenso, entre más arriba se habita en el hotel, mayor es su condena social, es decir, menos dinero posee.

Contrario a personajes como Jacobo Lince, que puede moverse como un turista por la ciudad y vivir en el espacio que desee, personajes como Andrés Zuleta y Virginia Buendía tendrán que buscar sus pasaportes para poder ingresar a Paradiso. Andrés lo logra vinculándose a trabajar en la Fundación $\mathrm{H}$ (fundación que trabaja por los Derechos Humanos) y Virginia Buendía, mujer del Sector C, gracias a sus contactos en el mundo del hampa. Esta búsqueda desesperada de ingresar a Paradiso ratifica la importancia figurativa del cronotopo asignada por Bajtín, pues construye una imagen simbólica de los latinoamericanos que buscan emplearse en países del "primer mundo" en busca de mejores oportunidades de trabajo.

El espacio narrado emerge a partir de la movilidad y el comportamiento de los sujetos en la ciu- dad, del uso y disposición que hacen del mismo. El espacio salta a primer plano a partir de la sentencia de muerte que ronda a los personajes cuando transgreden la norma y los espacios. Esto se evidencia en acciones concretas, por ejemplo, Andrés Zuleta será arrojado por el Salto de los Desesperados cuando intenta registrar a los matones de la Secur que torturan a alguien. De esta manera, el espacio se convierte en una especie de ayudante para el crimen y la impunidad.

\section{El espacio dialogado}

Un diálogo entre el arquitecto Bruno Palacios y Jacobo Lince resulta revelador de todo el cinismo político que gobierna a favor de unas castas sociales y no del bien general. Este cinismo se produce en el marco de una ciudad que, siguiendo a Bauman, puede denominarse ciudad del entorno posmoderno, es decir, una polis que minimiza las responsabilidades sociales, dejando en manos de lo privado la responsabilidad de lo público.

-El ser humano es territorial y no puede abrir sus puertas a todos los demás- explicaba Palacios. Llega un momento en que algunos se quieren apartar. Los de abajo también pueden construir su propio espacio ideal, y prohibir la entrada de nosotros los de F.

A lo cual Jacobo Lince contesta:

-Aquí arriba quieren que haya libertad de movimiento de las mercancías, del capital, de las inversiones. Lo único que no debe tener libertad de movimiento son las personas. (p. 239).

De esta manera, Angosta se convierte en la imagen del mundo globalizado que, como nueva ideología capitalista de la modernidad tardía, propende a la mundialización del capital, pero restringe la movilidad de los sujetos. Además, el Sector F viene a constituir la asimilación artística de los países del primer mundo. Con la ciudad ficcional de Angosta asistimos al legado del barón Haussmann, que consiste, según lo estudia Richard Sennett ${ }^{\text {en }}$ "cambiar

9 Richard Sennett (1975) focaliza su estudio en París y Londres desde el siglo XVII, hasta el siglo XIX. En un primer libro Vida urbana e 
el panorama físico con el fin de alterar las pautas sociales" (1975, p. 108), de tal manera que el manejo del espacio se hace relevante en el control, prevención y protección del disturbio, de los extraños y diferentes. Evidencia, además, las contradicciones e inconsistencias del proyecto moderno que no logró consolidarse ni alcanzar la mayoría de edad. Es decir, si en algo podrían ratificarse los ideales modernos, como el de la igualdad, tendría que ser en la adecuación de los espacios. No es así.

Con la novela Angosta se asiste a la configuración de una ciudad donde impera la barbarie premoderna y el cinismo moderno. En Angosta el control y el orden se ejercerán a partir de la fuerza y la violencia y, como dice Richard Sennett, "es una terrible paradoja que la escalada de la discordia en violencia acabe por ser, en estas comunidades, el medio exclusivo para mantener la ley y el orden" (1975, p. 63). Así, con la política del Apartheid, transferida a los espacios cargados simbólicamente con su ideología, se desemboca en una polaridad espacial de corte antropológico: actitud fágica y actitud émica ${ }^{10}$.

identidad personal explora la constitución de la identidad personal a partir de la vivencia de la ciudad. Resulta importante en este estudio el mito de "falsa identidad comunitaria" que falsea la experiencia bajo el mito de un "nosotros" colectivo que es usado en la edad adulta como escudo para protegerse de la otredad. Así, las palabras de Bruno Palacio se refieren a un "nosotros" que mira con desconfianza, pero más con cinismo a los demás sectores de Angosta. De esa manera encuentra su justificación, su argumentación cínica, pues bien sabe que el factor económico es preponderante en la elección y admisión de los sujetos en la ciudad actual.

10 Al respecto, la definición que hace Levi-Strauss es la siguiente: “Antropoemia (del griego emeín 'vomitar' [...] consiste en expulsar a esos seres temibles fuera del cuerpo social manteniéndolos temporaria o definitivamente aislados, sin contacto con la humanidad, en establecimientos destinados a ese uso" (1970, p. 390). La segunda tendencia consiste en la antropofagia. Levi-Strauss señala que de todas las prácticas salvajes ésta es la que más nos inspira horror y desagrado. En primer lugar, dice el autor "se debe disociar las formas propiamente alimentarias, es decir, aquellas donde el apetito de carne humana se explica por la carencia de otro alimento animal, como ocurría en ciertas islas polinesias" (p. 380) Superado este estadio quedan "las formas positivas", que dependen de causas "místicas, mágicas o religiosas. Por ejemplo, la ingestión de una partícula del cuerpo de un ascendiente, de un fragmento de un cadáver enemigo para permitir la incorporación de sus virtudes o la neutralización de su poder". Las prácticas de la antropofagia "ven en la absorción de ciertos individuos poseedores de fuerzas temibles el único medio de neutralizarlas y aún de aprovecharlas" (p. 390).
Actitud émica en Angosta: esta actitud va a generar un tipo de espacio apto para su realización. En Angosta estará objetivada en la construcción literaria de la zona $\mathrm{C}$ y de la Zona T, pero su mayor tensión se ve con la imposibilidad de los personajes que laboran en la Zona F para el contacto, para hablar con los otros e incluso para dirigirse la palabra mutuamente. Asimismo, los habitantes del Sector C sólo pueden realizar trabajos de segunda o tercera como barrer o lavar baños, pero no para construir empresa. Como señala Bauman (2006, p. 1009), al reelaborar esta categoría para la ciudad contemporánea, "las formas superiores y "refinadas" (modernizadas) de la estrategia "émica" son la separación espacial, los guetos urbanos, el acceso selectivo a espacios y la ocupación selectiva".

En Angosta se objetiva la condición émica de sus habitantes, los cuales resultan vomitados y satanizados por la clase dominante, destinados a guetos y sectores deprimentes. La actitud fágica devora, mata, asesina a los intelectuales, a los defensores de Derechos Humanos, elimina el peligro para sus estructuras de poder, como sucede con el homicidio de Andrés Zuleta, el exterminio de la Fundación H y la quema de la Librería La Cuña. Todos los elementos que intenten poner en evidencia el cinismo moderno y la barbarie premoderna que gobiernan en Angosta serán destruidos, no hace falta mayor argumentación para rastrear esta situación en Colombia. En términos de hábitus, es decir, de los elementos de la vida del autor que se reproducen también de manera ficcional, Andrés Zuleta, sus ideales, su búsqueda de libertad y denuncia de injusticia conectan con la muerte de Héctor Abad Gómez en 1987 a manos de los paramilitares de Medellín. En la novela queda insinuado y su desarrollo se dará en la novela testimonial El olvido que seremos (2007). Sin embargo, no es necesaria tampoco una relación directa con su relato personal, basta recordar el exterminio de la Unión Patriótica como un acto deliberado y sistemático de la ultraderecha; la muerte de los sindicalistas, investigadores, maestros, la persecución cínica a las ONG que denuncian la violación de los Derechos 
Humanos o el genocidio que se viene cometiendo con las comunidades indígenas y campesinas por parte de guerrilleros, militares y paramilitares.

La configuración de Angosta como cronotopo se convierte en la posibilidad no sólo de unidad artística, sino la posibilidad figurativa del escritor para objetivar las problemáticas sociales a partir de las situaciones y del lenguaje. Se acerca a una estética que podría llamarse una estética del asfalto

\section{Bibliografía}

Abad Faciolince, H. (2003). Angosta. Bogotá: Planeta.

Bachelard, G. (1993). Poética del espacio. Bogotá: Fondo de Cultura Económica.

Bajtín, M. (1989). Teoría y estética de la novela. Madrid: Taurus.

Bauman, Z. (2004). Ética posmoderna. Buenos Aires: Siglo XXI Editores

Bauman, Z. (2005). Amor líquido: acerca de la fragilidad de los vínculos humanos. Buenos Aires: Fondo de Cultura Económica.

Bauman, Z. (2006). Modernidad líquida. Buenos Aires: Fondo de Cultura Económica de Argentina.

Bauman, Z. (1998). La tierra que atardece. Bogotá: Planeta.

Bauman, Z. y Testesr, K. (2002). La ambivalencia de la modernidad y otras conversaciones. Barcelona: Paidós.

Cruz Kronfly, Fernando (1994). La sombrilla planetaria. Bogotá: Planeta.

Gadamer, H. G. (2004). Hermenéutica de la modernidad. Conversaciones con Silvio Vietta. Madrid: Mínima Trotta.

García Canclini, N. (1990). Culturas híbridas: estrategias para entrar y salir de la modernidad. México: Grijalbo.

Giraldo, L. M. (2000). De la ciudad arcadia a la ciudad historia. En Narrativa colombiana. Búsqueda de en oposición al mundo narrado en la arcadia. Los suburbios, los guetos, el acecho de la muerte y la exclusión son los componentes de una novela que desde el título y el epígrafe anuncia lo estrecho, asfixiante, malogrado que implica vivir en la ciudad de hoy, pero no como algo terminado, sino como una procesión interminable, sugerida en la conjugación verbal inacabada de su enunciación, "iban": "iban oscuros por angosta tierra”, Virgilio. 기

un nuevo canon 1975-1995. Bogotá: Universidad Javeriana.

Levi-Strauss, C. (1970). Tristes trópicos. Buenos Aires: Eudeba. Editorial Universitaria de Buenos Aires.

Lotman, Y. (1970). Estructura del texto artístico. Madrid: Ediciones Istmo.

García Márquez, G. (2007). Cien años de soledad. Bogotá: Alfaguara.

Mijailov, M. I. (1978). La Revolución Industrial. Bogotá: Editorial Suramericana.

Pimentel, L. A. (2001). El espacio en la ficción. México: Siglo XXI Editores.

Rama, A. (1984). La ciudad letrada. Hanover: Ediciones del Norte.

Romero, J. L. (1999). Latinoamérica: las ciudades y las ideas. Medellín: Editorial Universidad de Antioquia.

Sennett, R. (1975).Vida urbana e identidad personal: los usos del desorden. Barcelona: Ediciones Península.

Universitas Humanista. (2003, julio diciembre). Bogotá: Universidad Javeriana, pp.11-27.

Von Humboldt, A. (2005) Vistas de las cordilleras. Señal que cabalgamos, 57, pp.

Von Martin, A. (1996). Sociología del Renacimiento. Bogotá: Fondo de Cultura Económica.

Zubiaurre, T. (2000). El espacio en la novela realista: paisajes, miniaturas, perspectivas. México: Fondo de Cultura Económica de México. 